\title{
StATUS REPORT OF NASA'S OCEANOGRAPHIC ACTIVITIES
}

$\mathrm{T}_{\mathrm{b}}$ TOPEX/POSEIDON: This dedicated altimeter mission, being pursued jointly with the French Centre National d'Etudes Spatiales, has been under development at the Jet Propulsion Laboratory (JPL) since its new start in FY 1987. It is proceeding on schedule for a December 1991 launch aboard an Ariane 4 rocket. The second meeting of the Science Definition Team (SDT), selected as a result of an Announcement of Opportunity (AO), was held in Paris the week of May 3, 1988.

NSCAT: Development of the NASA Scatterometer, originally to fly aboard the US Navy's NROSS satellite, was initiated in FY 1985; some flight hardware has already been delivered to the project at JPL. With NROSS now cancelled, a proposal to fly NSCAT has been submitted in response to a Japanese AO for flight aboard their Advanced Earth Observing Satellite (ADEOS). Action on this proposal is due late this July. ADEOS, planned for launch in mid-1993, offers what we feel to be a minimum overlap with TOPEX/ POSEIDON of about 18 months. Should NSCAT be selected for flight on ADEOS, there will be no change in data access for the research community. The NSCAT SDT has met three times, most recently this past October.

SEA-WIFS: The Compact Wide-Field Sensor, an improved version of the Coastal Zone Color Scanner on Nimbus-7, has been proposed for flight aboard Landsat- 6 in 1991. The Department of Commerce and EOSAT have signed a contract for the development of Landsat-6. NASA and EOSAT have agreed in principle to share funding for Sea-WiFS, and NASA is currently seeking support for this initiative. Under this agreement in principle, NASA has the right to data access for retrospective research use (as well as some support for real-time research cruise planning), while EOSAT has the right to sell the data for real-time operational use. Support for Sea-WiFS activities will be centered at the Goddard Space Flight Center.

ASF: The Alaska Synthetic Aperture Radar (SAR) Facility is under development at JPL for installation at the University of Alaska in Fairbanks to receive, process, archive and distribute SAR products from the European ERS1, Japanese ERS-1, and proposed Canadian Radarsat satellites, scheduled for launch in 1990, 1992, and 1994, respectively. Formal agreements are in place with both the Europeans and Japanese regarding the ASF. SAR observations of the Arctic sea ice are the main ASFrelated objective for our program.

Other activities include support on the part of the NASA Ocean Data System at JPL to develop a capability for installa- tion at the National Snow and Ice Data Center in Boulder to process, archive and distribute sea-ice products from the Special Sensor Microwave Imager (an improved version of the Nimbus-7 microwave radiometer) now flying on a Defense Meteorological Satellite.

Finally, discussions are underway with the European Space Agency regarding access to their ERS-1 data. We in NASA are interested in the U.S. scientific community having data access for retrospective research use, while interest in NOAA exists for having similar access to quick-look products for real-time operational use. We are exploring quid pro quo arrangements, whereby data and products from US satellites (such as noted above) might be exchanged for those from ERS-1. This satellite is scheduled for launch in May or June of 1990.

Contributed by W. Stanley Wilson, NASA

\section{Logo CONTEST}

It

I $t$ is fitting that the new society have an official logo to crown its correspondence and pepper its pages. Correspondingly, we hereby announce the Great Oceanography Society Logo Competition, the purpose of which is to choose an original artistic work that suitably represents the spirit, goals, and ambitions of the Society and its members. Contestants are encouraged to exercise their creative imaginations, keeping in mind the desirable principles of originality, expressiveness, simplicity, and good taste. Contributions can be in black-and-white or color. Line drawings, computer graphics, and abstract designs will be considered. We ask only that each contribution be limited in size to a single sheet of standard typewriter paper, be an original work signed by the artist, and be related in some way to the ocean. Contributions should be submitted before November 30, 1988 to the Secretary of the Society at the address given on the title page of the magazine. The panel of judges will be drawn from the Oceanography Society Council, augmented by qualified art critics as deemed appropriate. The judges ' final decision will be announced with appropriate fanfare at the first annual meeting of The Oceanography Society.

The judges reserve the right to reject all entries and continue the competition. The winner will receive free membership in the Society for three years, an award of considerable distinction, but one which pales in comparison with the pride of recognition that will last a lifetime.

$-D A B$ 